\title{
Sexual Risk behaviour and Associated Factors among Governmental Higher Institution Students in Debre Markos Town, North West Ethiopia
}

\section{Muleta Mekonnen ${ }^{1 *}$, Belete Yimer $^{1}$ and Awraris Wolde ${ }^{2}$ \\ ${ }^{1}$ Department of Public Health, Debre Markos University, Ethiopia \\ ${ }^{2}$ Department of Statistics, Debre Markos University, Ethiopia}

*Corresponding author: Muleta Mekonnen Nikus, Department of Public Health, Debre Markos University, Ethiopia, Email:mulettkoo@gmail.com

\section{Research Article}

Volume 2 Issue 1

Received Date: November 27, 2017

Published Date: April 16, 2018

DOI: $10.23880 /$ phoa- 16000121

\section{Abstract}

Sexual and reproductive health problems are among the main causes of death, disability, and disease among young people worldwide particularly in Africa. This study aimed to assess sexual risk behaviour and associated factors among governmental higher institution students in Debre Markos town, North West Ethiopia.

Methods: A cross sectional study design was applied among randomly selected 774 students in Debre Markos town. Data was collected using validated, pre coded, pre tested, and self-administered questionnaire on youth risky sexual and reproductive behavior. The analysis contains descriptive statistic, bi-variate and multivariate logistic regression.

Results: In this study $33.3 \%$ of the respondents were sexually active. Seventy nine $(33.2 \%)$ have multiple partner, 93(39.1\%) had used condom inconsistently and (13.9\%) had sexual contact with commercial sex workers. The overall prevalence in the last 12 months was 42.0\%. Peer pressure [AOR3.23(2.42,5.05)], chat chewing [AOR:3.14(1.34,6.08)], alcohol use [AOR2.67(1.59,4.82)], living arrangement [AOR:3.04(1.79,8.44)], religious attendance [AOR:0.71(0.55,0.92)] and participating in health related club [AOR: $0.364(0.182,0.73)]$ were associated with sexual risk behaviours.

Conclusion: Considerable number of governmental higher institution students in the study area had practiced sexual risk behaviours. So school based reproductive health interventions like negotiate condom use, youth friendly sexual and reproductive health services are needed to prevent sexual risk behaviours.

Keywords: Students; Adolescents; Higher Institution; Risky sexual behavior; Predictors; HIV/AIDS

Abbreviations: SRH: Sexual and Reproductive Health; Proportional to Size.

STIs: Sexually Transmitted Infections; PPS: Probability 


\section{Introduction}

Sexual risk behaviour is any sexual activity that increases the risk of contracting HIV or other STI or becoming pregnant. Sexual risk behaviour includes unprotected sexual activity, inconsistent use of condoms, sex with multiple partners, and sex for material gain [1]. Sexual and reproductive health (SRH) is among the most fundamental aspects of life [2,3]. Globally, 45 percent of all new HIV infections worldwide are occurring among young people aged 15 to 24 years, 500,000 young people are infected with an STI per day, approximately 80 million women have unwanted pregnancies every year [2-10]. Sexuality and Young adults: HIV/AIDS is affecting most productive segments of the population that form the basic education sector which is vital to the creation of human capital this will affect both the demand and supply of education [4]. Studies revealed that living arrangements, educational level, peer pressure, and religious attendance, having pocket money, showed significant association with the risk behaviours [11-17]. Peer pressure, Alcohol and Substance use: Peer pressure was reported as factor that lead to the first sexual encounter accounting for $35.2 \%$ of sexually active, alcohol (11.5\%) and other substances (10.3\%) [17]. Study among university students shows substance use is associated with increased risk sexual behaviour [13]. Nowadays meeting the needs of youth is becoming more critical for a wide range of policy makers and programmers because the continuous and dynamic change of actions of young people which will shape the size, health, and prosperity of the world's future population. The problems of HIV/AIDS and other sexually transmitted infections (STIs) among youths indicating more efforts are needed toward sexual and reproductive health risk reduction interventions particularly of higher institutions students. Studies conducted among higher institutions students in Ethiopia about sexual risk behaviour were limited and also there is no study done regarding sexual risk behaviour of the students at the study area. Therefore, to inform decision (policy) makers, local program /school managers, community and parents, it is sound to assess sexual risk behaviour and associated factors among the students in higher institutions. Thus, the objective of this study was to assess sexual risk behaviour and associated factors among governmental higher institution students in Debre Markos town, North West Ethiopia.

\section{Methods and Materials}

Study setting, design and period: A cross-sectional study design was employed from March 29 to April 6, 2013.The study was conducted in Debre Markos Town, Amhara Regional state, North West Ethiopia. Debre Markos town have three governmental higher institutions which include one university, one TTC and one TVET.

\section{Study Population, Sample Size and Sampling}

All regular students of governmental higher institution in Debre Markos town were the study population. A sample size of 774 was determined using single population proportion formula by taking prevalence of inconsistent condom use of $35.5 \%$ among Jimma university students (16) with a 95\% confidence level, 5\% margin of error, and by considering a non-response rate of $10 \%$. This study was based on the random sample of thirteen departments of the forty six departments existing in the Debre Markos governmental higher institutions. The total departments in the higher institutions were initially stratified into health and non-health departments. Then, thirteen (six from Debre Markos University; one from health and five from non-health departments, three from TTC and four from TVET colleges which are non-health departments) were selected randomly based on Probability Proportional to Size (PPS) sampling technique and then the determined sample size was distributed proportional to total students of each batch. After that, simple random sampling was used to select the required number of students using list of students ID number in their respective batch.

\section{Data Collection Methods and Procedures}

Data collection was done by validated pre tested, pre coded, and self- administered questionnaire with combined closed and open-ended questions on youth risky sexual and reproductive behavior and data was collected by trained six diploma nurse and facilitated by trained supervisors.

\section{Data Processing and Analysis}

The collected data was, entered into EPI -INFO version 6 and Transferred and analysed using SPSS version 16. The analysis part contains frequencies, cross tabs, bivariate, and multiple logistic regressions. OR and 95\% CI was constructed along with corresponding $\mathrm{p}$-value.

\section{Ethical Consideration}

Ethical clearance was obtained from the respective institutions, informed consent was obtained and confidentiality was maintained for the participants. 


\section{Results}

Socio-demographic characteristics: From the total 714 completed the questionnaire adequately making the response rate of $92.25 \%$. The mean age of the students was 20.58 with standard deviation of +1.99 (Table 1 ).

\begin{tabular}{|c|c|c|}
\hline Variables & Number & Percent (\%) \\
\hline \multicolumn{3}{|c|}{ Sex } \\
\hline Male & 439 & 61.5 \\
\hline Female & 275 & 38.5 \\
\hline \multicolumn{3}{|c|}{ Age group } \\
\hline $15-19$ & 163 & 17.8 \\
\hline $20-24$ & 524 & 57.1 \\
\hline $25-29$ & 20 & 2 \\
\hline$\geq 30$ & 7 & 0.8 \\
\hline \multicolumn{3}{|c|}{ Religion } \\
\hline Orthodox & 615 & 86.1 \\
\hline Muslim & 57 & 8 \\
\hline Protestant & 37 & 5.2 \\
\hline Catholic & 5 & .7 \\
\hline \multicolumn{3}{|l|}{ Marital status } \\
\hline Single & 646 & 90.5 \\
\hline Married & 64 & 9.0 \\
\hline Others & 4 & 0.5 \\
\hline \multicolumn{3}{|c|}{ Ethnicity } \\
\hline Amhara & 593 & 83.1 \\
\hline Oromo & 58 & 8.1 \\
\hline Tigrie & 33 & 4.6 \\
\hline Others & 30 & 4.2 \\
\hline \multicolumn{3}{|l|}{ Residence } \\
\hline Rural & 443 & 62.0 \\
\hline Urban & 271 & 38.0 \\
\hline \multicolumn{3}{|c|}{ Institution } \\
\hline University & 408 & 57.1 \\
\hline TVET & 154 & 21.6 \\
\hline TTC & 152 & 21.3 \\
\hline \multicolumn{3}{|l|}{ Field of study } \\
\hline Non health & 624 & 87.4 \\
\hline Health & \begin{tabular}{|c|}
90 \\
\end{tabular} & 12.6 \\
\hline \multicolumn{3}{|c|}{ Living arrangement } \\
\hline Live without families & 502 & 70.4 \\
\hline Live with families & 212 & 29.6 \\
\hline \multicolumn{3}{|c|}{$\begin{array}{ll}\text { Year of education } \\
\end{array}$} \\
\hline First year & 320 & 44.8 \\
\hline Second year & 206 & 28.9 \\
\hline Third year & 188 & 26.3 \\
\hline
\end{tabular}

Table1: Distributions of students by their Socio demographic characteristics, D/Markos, March, 2013.
Sexual characteristics: Out of 714 respondents, 238 $(33.3 \%)$ reported they were sexually active. The mean age at first intercourse was $18.3(+1.8 \mathrm{SD})$ years and the mean age of sexual Commencement for males and females were $18.7(+1.8 \mathrm{SD})$ and $18.0(+1.84 \mathrm{SD})$ respectively. The Minimum age at first intercourse for males and females were 14 and 12 years, respectively (Figure1).

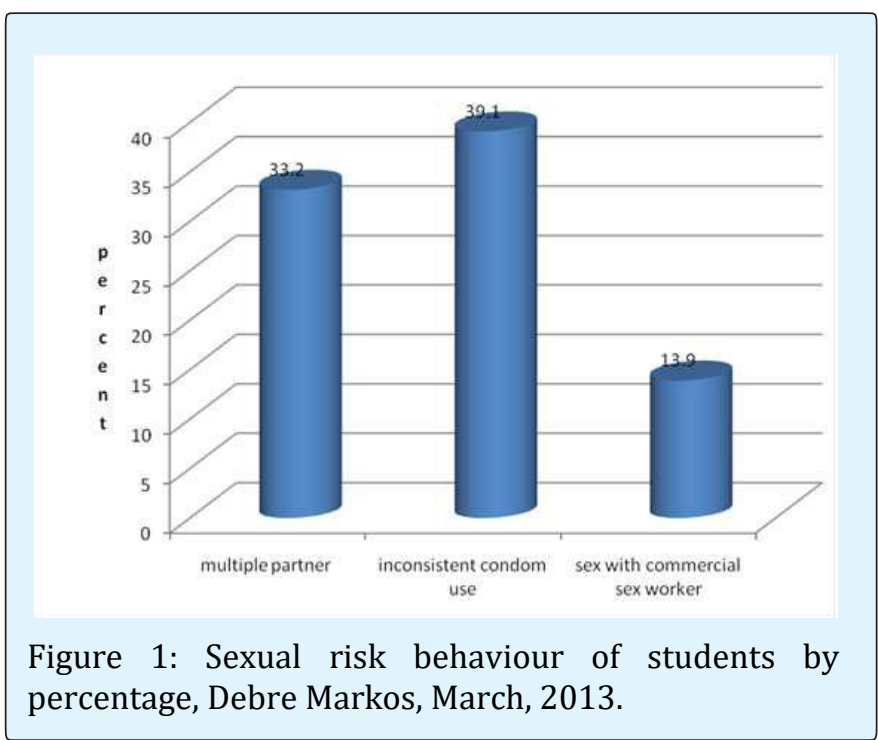

Reasons for first sexual encounter includes love 94 (39.1\%), sexual desire $70(29.5 \%)$, peer pressure 32 $(13.5 \%)$, got married $32(13.5 \%)$, rape $6(2.5 \%)$ and drunk 4 (1.7\%). First sexual partner friend $128(54.2 \%)$, causal partner 68(28.8\%), husband/wife $30(12.7 \%)$ and commercial sex workers 10 (4.2\%). Mean number of partners was $1.90(+0.33)$ and $1.87(+0.30)$ for males and females respectively (Figure 2 ).

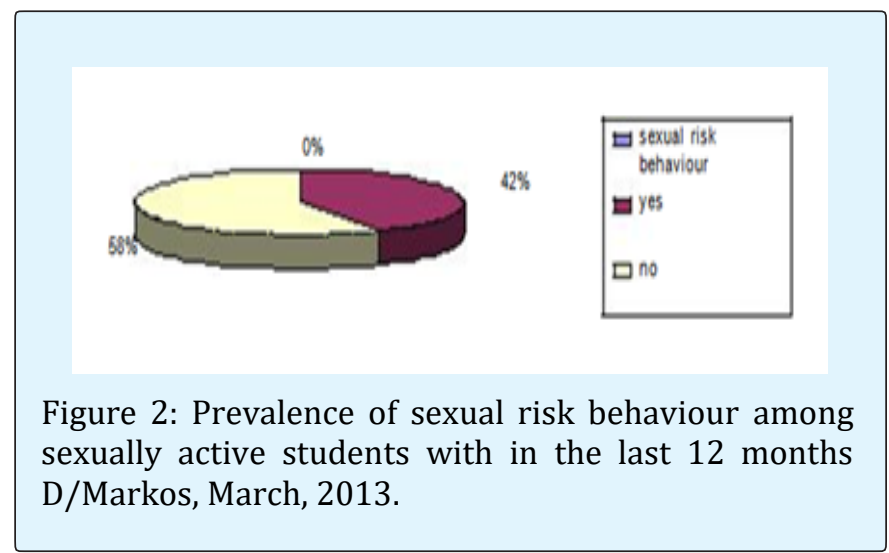


Among sexually active respondents, about $33.6 \%$ used condom at first sex, 141 (59.2\%) have ever used condom, $39.1 \%$ used condom inconsistently in the last 12 months. Of sexually active 165 (69.3\%) answered they used when suspect their causal partner, 17 (7.1\%) while doing sex with commercial sex workers and $40(16.8 \%)$ when doing sex with boy/girlfriends (Figure 3 ).

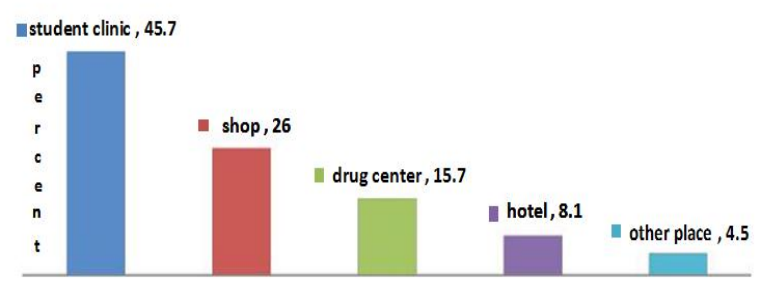

Figure 3: Percentages of students by preferred place to get condom, D/Markos, 2013.

Reasons for not using condom were not available at time 51 (51.4\%), dislike 29 (27.1\%) and 23 (21.5) of them reported believe their partners.

Predictors of sexual risk behaviors: The unadjusted analysis of the associations of sexual risk behaviors with variables selected for multivariable model are presented in third and fourth columns of table 2. Students who drink alcohol were 2.67 times more likely to have sexual risk behaviours as compared to those did not drunk [AOR: $2.67(1.59,4.83)]$ and students chewing chat were 3.14 times more likely to have sexual risk behaviours as compared to those don't chew [AOR: $3.14(1.34,6.08)]$. Students who live without family were 3.04 times more likely to had practiced sexual risk behaviours as compared to those who live with family [AOR: 3.04 $(1.79,8.44)$. Students who were pressurized by their peers were 3.23 times more likely to have sexual risk behaviour as compared to those don't pressurized by their peers [AOR:( $3.23(2.42,5.05)]$. Those students participating in health related club at school were $63.6 \%$ less likely to have sexual risk behaviours as compared to those who do not [AOR: $0.364,95 \%$ CI: $(0.18,0.73)]$. Students those who attend religious activity were $28.9 \%$ less likely to have sexual risk behaviours as compared to those don't [0.71(0.55, 0.92)] (Table 2).

\begin{tabular}{|c|c|c|c|c|c|}
\hline \multirow[t]{2}{*}{ Variables } & \multicolumn{2}{|c|}{ Sexual risk behavior } & \multirow[t]{2}{*}{ Crude OR(95\%CI) } & \multirow[t]{2}{*}{$\operatorname{AOR}(95 \% \mathrm{CI})$} & \multirow[t]{2}{*}{ P-value } \\
\hline & Yes & No & & & \\
\hline \multicolumn{6}{|c|}{ Living arrangement } \\
\hline Without families & $80(57.6)$ & $59(42.4)$ & $5.36(1.22,4.71)$ & $3.04(1.79,8.44)$ & 0.005 \\
\hline With families & $20(20.2)$ & $79(79.8)$ & 1 & 1 & \\
\hline \multicolumn{6}{|c|}{ Participation in health related club at school } \\
\hline Yes & $54(39.4)$ & $83(60.6)$ & $0.78(0.508,0.943)$ & $0.36(0.182,0.726)$ & 0.004 \\
\hline no & $46(45.5)$ & $55(55.5)$ & 1 & 1 & \\
\hline \multicolumn{6}{|c|}{ Alcohol use } \\
\hline yes & $52(59.8)$ & $35(40.2)$ & $3.19(1.672,6.904)$ & $2.67(1.591,4.827)$ & 0.014 \\
\hline no & $48(28.5)$ & $103(71.5)$ & 1 & 1 & \\
\hline \multicolumn{6}{|c|}{ Chat chewing } \\
\hline Yes & $42(63.6)$ & $24(36.4)$ & $3.44(1.326,7.891)$ & $3.14(1.340,6.080)$ & 0.001 \\
\hline No & $58(33.7)$ & $114(66.3)$ & 1 & 1 & \\
\hline \multicolumn{6}{|c|}{ Peer pressure } \\
\hline Yes & $51(62.9)$ & $30(37.1)$ & $3.75(1.28,7.88)$ & $3.23(2.419,5.05)$ & 0.001 \\
\hline No & $49(31.2)$ & $108(68.8)$ & 1 & 1 & \\
\hline \multicolumn{6}{|c|}{ Religious attend } \\
\hline Yes & $82(41.0)$ & $118(59.0)$ & $0.49(0.59,0.83)$ & $0.71(0.55,0.92)$ & 0.001 \\
\hline No & $28(58.3)$ & $20(41.7)$ & 1 & 1 & \\
\hline
\end{tabular}

Table 2: Bivariate and Multivariate analysis results of associated factors of sexual risk. 


\section{Discussion}

Few researches in Ethiopia revealed that sexual risk behaviour among higher institution students were high $[13,16]$. The prevalence of sexual risk behaviours among sexually active students in this study was (42.0\%) with slightly higher among females as compared to males which may be due to differences of negotiation skills of condom use and of resisting peer pressure in these sex groups among others.

Includes 33.2\% multiple partners, 39.1\% used condom inconsistently, and $13.9 \%$ have had sex with commercial sex workers. In line with research among Uganda university students that revealed $46 \%$ of males and $23 \%$ of females have multiple partners and $32 \%$ of males and $38 \%$ of females were use condom inconsistently [18]. But not inline when compared with the result among Nigeria medical students which was $65 \%$ use condom, $6.1 \%$ had multiple partner and only $3.8 \%$ have had sex with commercial sex workers. The possible reason might be due to difference in field of study which might bring safe behaviour for those of Nigeria medical students $[19,20]$.

According to this study multiple partners (33.2\%) was slightly higher when compared with the study among Jimma university students (28.9\%) and those students have contact with commercial sex workers was higher among Jimma university students (18.7\%) as compared to this result $(13.9 \%)[13,16]$. The possible logical reason might be the difference in population living arrangements and institutions. But this result was better compared with the result among Haramaya university students which was $48.9 \%$ of them ever had sex, multiple partner $34.6 \%$ and $43.2 \%$ of the students ever had used condom and only $16.2 \%$ used consistently. The possible logical reason might be due to the different IEC/BCC programs that could possibly increase awareness of the students on sexual behaviour.

Regarding condom utilization in this study was $59.2 \%$ ever had used condom which was in line with the study among young adult in Dessie town which is $56.8 \%$ ever had used condom and $25.5 \%$ of respondents used condom consistently [21]. But higher when compared with the result from Haramaya university students which is $43.2 \%$ ever had used condom and $16.2 \%$ used consistently. Also higher compared to Gondar collage of medical students which were $37.1 \%$ ever had used condom and only $6.4 \%$ used condom consistently. But those had sex with commercial sex worker was $7.8 \%$ which is less than this study $13.9 \%$ [17] and also this result were higher compared to the findings among college students in Addis Ababa which was $17.9 \%$ of the students have used condom consistently and condom utilization of the students at first sex in this study was $33.6 \%$. The possible logical reason could be time gap between the studies and increased awareness about condom utilization and safe sexual behaviour $[13,16,21-23]$.

Inconsistent condom use (39.1\%) in this result was higher when compared with Jimma university students (35.5\%) and lower when compared with college students in Addis Ababa which was (66\%) [23]. The possible logical reason might be due to difference in population living arrangements and institutions.

Those students who have peer pressure were 3.23 times more likely to have sexual risk behaviour [AOR: $3.23(2.419,5.046)]$. This study was supported by study among female undergraduate students of Nigeria which is $33 \%$ was influenced by their peers but higher compared to this study which is $(13.5 \%)$ was influenced by their peers [24-27]. This result was also supported by result among youth in Addis Ababa 35.2\% among sexually active youth. This is also higher when compared to this result (13.5\%). Possible reason could be due to their social dependency on their peers and the difference might be due to improved peer education and time gap.

Students who drink alcohol were 2.67 times more likely to have sexual risk behaviour as compared to those who didn't drink alcohol [AOR : 2.67(1.591, 4.827)] and students who chew chat were 3.14 times more likely to have sexual risk behaviour [AOR: 3.14(1.34, 6.08)]. This was supported by study among Burkinafaso students that $33 \%$ used alcohol and $46.4 \%$ of Jimma university students that used alcohol which is lower than this study that $51.4 \%$ used alcohol $[13,28]$. About $25 \%$ of Jimma University students reported that have had chew chat which is higher than this study that $14.3 \%$ chaw chat [13]. This was also supported by study among students in Ghana that among the youth 14 who reported having had risky sex in the last 12 months, $44 \%$ used alcohol and chat regularly. The possible reason for the difference might be difference in population composition and study area.

Those students live without family were 3.04 times more likely to have sexual risk behaviour as compared to those students live with their family [AOR: (3.035(1.79, 8.44]. This was supported by study among secondary school in Ethiopia [17,21,29-31]. The possible logical reasons might be parental control have protective effect on the behaviour of the students. 
Those students participate in health related club in school were $63.6 \%$ less likely to have sexual risk behaviours as compared to those didn't participate [AOR: $0.364,95 \%$ CI: $(0.182,0.726)]$. This is supported by study among Jimma university students and studies among secondary school in Ethiopia [2,6]. This could be the fact that participating in health related club in school might create better awareness about their sexual behaviour and also peer educators are effective agents in bringing desired behavioural change.

Those students who frequently attend religious service were $28.9 \%$ less likely to have sexual risk behaviour as compared to students who didn't attend [0.711(0.549, 0.922)].This was supported by the study on socio demographic factors and correlates of sexual risk behavior among youth across Ethiopia [17,21,29-31]. Also supported by study among Uganda University students. The reason might be Students will change their behaviors in response to the true expectations of others [32-40].

The major strengths of this study were, as the study was based on self-administered questionnaire on students' risky sexual behavior, there might not be cultural unacceptability and fear of disclosing issues which may minimize social desirability bias and random selection of the institutions and/or study participants both of which may made generalization possible to study population [41-43]. While this type of study design is appropriate for establishing the prevalence data, and has some mentionable advantages, it has been demonstrated previously that it is difficult to establish cause -effect relationship between the study outcome and exposure variables $[44,45]$.

\section{Conclusion and Recommendation}

Considerable number of students of governmental higher institution students in Debre Markos town had practiced sexual risk behaviour. Peer pressure, chat chewing, alcohol use, living arrangement, religious attendance and participation in health related club in school were the major associated factors for sexual risk behaviours among the students.

Policy makers need to focus on prevention strategy on those behaviours and systems which have strong bond with young people, like teaching institutions, other youth centered institutions and parties that engage in them like parents and other key actors in the life of young peoples. Institutions and other non-governmental organizations are need to plan and promote efforts to increase young people's life skills and access to reproductive health services, youth centers, safe education and recreational facilities. They should also encourage the existing health institutions to provide youth friendly services, negotiate condom utilization and also encouraging peer education related to sexual behavior and need to create an enabling environment or environmental interventions such as control alcohol drinking and chat chewing and give attention to youth clubs like HIV/AIDS or other clubs, building their capacity and providing comprehensive, accurate and timely information to members and peer educators. Parents and other key peoples should be involved in HIV/AIDS related intervention activities. Encouraged to participate and encouragement of open communication between parents and their children will help to reinforce behaviour.

\section{Competing Interests}

The authors declare that they have no competing interests.

\section{Authors Contributions}

Muleta Mekonnen, Belete Yimer and Awraris Wolde were participated in the conception, design, and data collection, analyzed the data and drafted the paper. They were also approved the proposal with some revisions, participated in data collection and analysis, commented on the analysis and improved the first draft. All authors revised subsequent drafts of the paper.

\section{Acknowledgment}

Our earnest gratitude goes to, Debre Markos University, Debre Markos TTC college and Debre Markos TVET college administration, data collectors and study participants for their cooperation and assistance. Our Special thanks staff members for their unlimited contribution and support for the success of this paper.

\section{References}

1. Aral, IOM Sexual risk behavior among adolescent women.

2. Pathfinder international (2003) Youth-Friendly Sexual and Reproductive Health Services: An Assessment of Facilities. African youth alliance.

3. Avert (2010) Introduction to global AIDS epidemics. 
4. USAID (2006) Assessment of Youth Reproductive Health and HIV/AIDS Programs in Kenya. Family Health International.

5. UNAIDS (2008) Report on the global AIDS epidemic.

6. Yohannes. A, Moges A (2006) The impact of HIV/AIDS information disseminated on the status of behavioral change brought among Jimma University students. Ethiop J Educ \& Sc 2(1): 1-20.

7. Champion J, Shain R, Piper J, Perdue T (2001) Sexual abuse and sexual risk behaviours of minority women with sexually transmitted diseases. Western Journal of Nursing Research 23(3): 241-254.

8. Chin D (1999) HIV-related sexual risk assessment among Asian/Pacific Islander American Women: An Inductive Model. Soc Sci Med 49(2): 241-51.

9. Christianson M, Johansson E, Emmelin M (2003) Onenight stands - Risky tips between lust and trust: Qualitative interviews with Chlamydia trachomatis infected youth in North Sweden. Scand J Public Health 31: 44-50.

10. Coley R, Medeiros B, Schindler H (2008) Effects of parenting on adolescent sexual risk behaviors. Journal of Adolescent Health 43: 133-140.

11. Tilahun T, Mariam M, Demissie A (2007) KAP on reproductive health problems among students of Jimma University and Jimma teachers' college.

12. Avert (2010) Introduction to global AIDS epidemics.

13. Walque D, Kline R (2009) Comparing condom use with different types of partners: national HIV surveys in Africa; Washington DC, World Bank.

14. Jacqueline D (2008) HIV/AIDS challenges among the youth in tertiary institutions in Kenya.

15. Otaala B (2003) Institutional policies for managing HIV/AIDS in Africa.

16. Belachew T, Jira C, Mamo Y (2004) KAP about HIV/AIDS and VCT among students of Jimma University. Ethiopia Journal of health sciences 43: 53.

17. Eshetu F, Zakus D, Kebede D (1997) The attitudes of students, parents and teachers 53 towards the promotion and provision of condoms for adolescents in Addis Ababa. Ethiopia J Health Dev 11(1): 7-16.
18. Agardh A, Emmelin M, Muriisa R, Ostergren PO (2010) Social capital and sexual behavior among Ugandan university students. Global Health Action $3(1)$.

19. Flannery D, Ellingson L (2003) Sexual Risk Behaviors among First Year College Students, 2000-2002 Californian Journal of Health 1(3): 93-104.

20. Daniyam CA, Agaba PA, Agaba EI (2010) sexual behaviour of medical students. A single institutional survey. Afr Health Sci 10(2): 150-153.

21. Yode M (2007) Association between age at first intercourse, sexual behaviour and sexually transmitted Infections among adolescents. pp: 1-5.

22. Negash B (2005) Predictors of condom use by using health belief model. pp: 64 .

23. Petro's B, Belayneh, Mekonnen Y (1997) AIDS and college students in Addis Ababa. A study conducted on knowledge, attitude and behaviour. Ethiop J Health Dev 11(2): 115-123.

24. Jacqueline D (2008) HIV/AIDS challenges among youth in tertiary institutions in Kenya.

25. Path finder international. Youth and HIV/AIDS fact sheet accessed from.

26. Okonkwo PI, Fatusi AO, Ilika AL (2005) Perception of peers' behaviour regarding sexual health decision Making among female undergraduates in Anambra State, Nigeria. Afr Health Sci 5(2): 107-113.

27. Wang B, Li X, Stanton B, Kamali V, Naar-King S, et al. (2007) Sexual attitudes, pattern of communication, and sexual behavior among unmarried out-of-school youth in China. BMC Public Health 7: 189.

28. Johannes J Langba, Alex E (2004) Alcohol, Drug Use, and Sexual-risk Behaviors among Adolescents: International Drug Control Program.

29. Robert JM, Ali MK, Lisa AW, Katherine CB, Musunda L, et al. (2001) Reproductive health risk and factors among youth in Lusaka, Zambia. Journal of Adolescent Health 30(1): 76-86.

30. Mohammed A, Youth RH (2007) Problems and Service in Lalibela, AAU. 
31. Teshager S (2005) Determinants of Risky Sexual Behavior among School.

32. African news (2010) Safer sex by young in Africa drives HIV rates down.

33. Farmer M, Meston C (2006) Predictors of condom use self-efficacy in an ethnically diverse sample. Arch Sex Behav 35(3): 313-326.

34. Fischtein D, Herold E, Desmarais S (2007) Sexual attitudes and behaviors. A survey of Canadian adults. Archives of Sexual Behavior 36: 51-461.

35. Flannery D, Ellingson L, Votow KS, Schaefer EA (2003) Anal intercourse and Sexual risk factors among college women, 1993-2000. Am J Health Behav 7(3): 228-234.

36. Freda MM, Damus K, Merkatz IR (1999) Evaluation of the readability of ACOG patient education pamphlets. The American College of Obstetrics \& Gynecology 93(5): 771-774.

37. Gebhardt WA, Kuyper L, Dusseldorp E (2006) Condom use at first intercourse with a new partner in female adolescents and young adults: The role of cognitive planning and motives for having sex. Aech Sex Behav 35(2): 217-223.

38. Harris L, Omam RF, Vesely SK, Tolma EL, Aspy CB, et al. (2007) Associations between youth assets and sexual activity: Does adult supervision play a role? Child: care. Health Dev 33(4): 448-454.

39. Mekonnen J Mequanente S (2009) KAP survy on substances abuse among preparatory students in Fogera district. Pharmacologyonline1: 144-152.

40. Nicholas S C N (2010) Predicting Youth Sexual Deviance: The Case of Risky Sexual Behaviour among Adolescents in Ghana.

41. Giles M, Liddell C, BydawelL M (2005) Condom use in African adolescents. The role of individual and group factors. AIDS Care 17(6): 729-739.

42. Edméa RT, Antonio Carlos de Albuquerque Bandeira \& Maria do Carmo Medeiros (1999) AIDS prevention condom use and perceptions among college students. Medicina Ribeirão Preto 32: 316-325.

43. Margaret W, Ruth B (2001) Sexual Behaviour and Condom Use in the Context of HIV Preventation Kenya. (42).

44. Rotermann M (2008) Trends in teen sexual behaviour and condom use. Health Rep 19(3): 53-57.

45. Amar K, Manoj S (2010) Determinants of safer sex behaviours among college students. Acta Didactica Napocensia 3(1): 27-38. 